\title{
Clinical features and survival in individuals with trisomy 18: A retrospective one-center study of 44 patients who received intensive care treatments
}

\author{
GEORGE IMATAKA, HIROSHI SUZUMURA and OSAMU ARISAKA \\ Department of Pediatrics, Dokkyo Medical University School of Medicine, Shimotsuga, Tocihgi 321-0293, Japan
}

Received November 10, 2015; Accepted January 21, 2016

DOI: $10.3892 / \mathrm{mmr} .2016 .4806$

\begin{abstract}
Trisomy 18 syndrome is a common autosomal aneuploidy chromosomal abnormality caused by the presence of extra chromosome 18 that leads to malformations of various parts of the body. In this study, we retrospectively investigated the effect of the medical progression and prognosis of 44 cases of trisomy 18 , admitted to our neonatal intensive care unit between 1992 and 2013. The patients were divided into group A ( $n=20,1992-2002)$ and group $B(n=24,2003-2012)$. Following delivery, karyotype, gender, gestational weeks, birth place, cesarean section, Apgar score and birth weight were analyzed using the Fisher's exact test, unpaired t-test and Mann-Whitney U test. Based on the statistical results, a comparison was made of the two groups and no significant differences were observed. Clinical data of major complications, mechanical ventilation, discharge from hospital and survival days were reviewed for the cases of trisomy 18 . Of the 44 patients, 42 had cardiac anomaly, 16 had esophageal atresia, and 3 patients had brain anomaly. Ventilation treatment was performed in 29 cases $(65.9 \%)$ and an increased percentage was identified in group B patients. The percentage survival was estimated using Kaplan-Meier curves and the two groups were analyzed using the generalized Wilcoxon test. Improvement in life prognosis was observed in group B as compared to group A. The log-rank test was used to assess survey periods of 180 days, 1 year, and the entire observation period. Although significant differences were observed for the prognosis of trisomy 18 at 180 days after birth, after 1 year and the entire survey period after birth, the significant differences were not confirmed. In conclusion, results of the present study provide information concerning genetic
\end{abstract}

Correspondence to: Dr George Imataka, Department of Pediatrics, Dokkyo Medical University School of Medicine, 880 Kitakobayashi, Shimotsuga, Tocihgi 321-0293, Japan

E-mail: geo@dokkyomed.ac.jp

Key words: prognosis, natural history, trisomy 13, neonatal intensive care unit, Edwards syndrome counseling for parents/guardians and life prognosis, prior to applying intensive management to newborns with trisomy 18 .

\section{Introduction}

The treatment strategy of trisomy 18 is controversial as the prognosis is lethal. Approximately 50\% of newborns survive $>1$ week while $>90 \%$ do not survive beyond 1 years of age. The medical progression of neonatal intensive care management in Japan has been previously established and the first described trisomy 18 infants were reported in $1960(1,2)$. The definition of the trisomy 18 syndrome, also known as common autosomal aneuploidy chromosomal abnormality due to the presence of an extra chromosome 18, using the standard G-banded karyotype allows for confirmation of the clinical diagnosis of multiple anomalies (3). It is clinically associated with various major and minor multisystem anomalies, including cardiovascular, brain with neurological, renal, gastrointestinal, respiratory, and skeletal malformations $(4,5)$. Trisomy 18 is clinically associated with $\geq 50 \%$ of anomalies including craniofacial abnormalities such as prominent occiput, narrow bifrontal diameter, low-set and malformed auricles and micrognathia; hand and feet anomalies including clenched hand, overlapping of index finger and hypoplasia of nails; thorax deformities; inguinal hernia; small pelvis; male with cryptorchidism; cardiac and circulatory system, in particular ventricular septal defect (VSD), patent ductus arteriosus (PDA) and auricular septal defect. In addition, $10-50 \%$ of cases showed other craniofacial, hand, feet and thorax anomalies, cardiac with pulmonic stenosis, coarctation of aorta, renal anomaly with horseshoe defect, double ureter, hydronephrosis and polycystic kidney, while $\geq 50 \%$ of cases exhibited central nervous system anomaly with cerebellar hypoplasia, agenesis of corpus callosum, hydrocephalus, meningomyelocele and Dandy-walker malformation $(6,7)$. All the cases had severe mental and psychomotor disorders.

Epidemiologically, previously conducted studies have focused on trisomy $18(4,8-23)$. Root and Carey (9) reported that the incidence of trisomy 18 syndrome is as low as 1 in 8,000 births; however, this is the second highest incidence of chromosomal aberrations in live-born infants following trisomy 21 . Findings of prevalence studies by 
Goldstein and Nielsen (10) Forrester and Merz (11) focusing on populations in Hawaii and Denmark, respectively, showed that live-born infants of trisomy 18 had an incidence of 1 in 8,000 to 1 in 10,000. By contrast, Bergin et al (12) reported the incidence of trisomy 18 to be 1 of 555 conceptuses, with the most recently recorded frequencies in live-born infants in Dublin and Leicester in England being in the range of approximately 1 in 3,000. On the basis of the reported literature, the live birth prevalence of trisomy 18 ranges from $1 / 3,000$ to $1 / 10,000$ and the estimated average is approximately 1 in 6,000 (3,9-12). Gender differences during gestation have been previously identified, with a 4-fold higher incidence in female subjects compared to male subjects (5). By contrast, Kuroki and Kurosawa (24) reported no gender differences in trisomy 18, as indicated by data obtained from the prefecture birth defects monitoring program in Japan. An increase in the age of the parturient female leads to an increased risk of trisomy 21, as well as the development of trisomy. The recurrence risk of trisomy 18 has been analyzed and estimated at $<1 \%(25,26)$. The precise mechanism of this syndrome is known to develop from an error in maternal meiosis, with the chromosomal abbreviation being due to maternal origin in $~ 96 \%$ of cases of trisomy 18 (27).

When issues such as the medical treatment of newborns, genetic counseling and medical ethics arise, management with treatment strategy for this genetic trisomy syndrome is clinically essential (6). The life prognosis of trisomy 18 is controversial as the outcome is usually lethal. Patients with long-term survival of trisomy 18 exhibited severe pschyomotor developmental delay. Thus, any approach to the treatment strategy and policy of a third-trimester fetus and live-born neonate with trisomy 18 is complicated, resulting in controversial findings. The primary issue involves the complexity surrounding the decision-making process regarding the treatment strategy immediately following birth in newborns diagnosed with trisomy 18. Rasmussen et al (13), Crider et al (18) and Irving et al (19) reported that the important issues involved in the parental primary care of live-born infants with trisomy 18 is associated with a high neonatal and infantile mortality death rate. When a fetus is known to have trisomy 18 , delivery by cesarean section is avoided due to ethics issues, as indicated by Norup (28) in a study conducted in Denmark. The findings of that study showed consensus for physicians working in the perinatal and neonatal medical unit until 21 weeks with regard to trisomy 18 (28). Irving et al (19) reported that the prenatal diagnosis of trisomy 18 leads to a decision in support of pregnancy termination in $86 \%$ of cases (19). Sociologically, the medical treatment for the neonatal to infantile periods with disabilities was found to be different for various countries depending on factors such as culture, religion, human rights, law and views on bioethics. Traditionally, a non-intervention approach in the newborn management of trisomy 18 and 13 has been previously utilized. Bos et al (29) summarized these ethical issues, indicating that early diagnosis was extremely important for the avoidance of unnecessary surgical treatment. At present, trisomy 18 and 13 are considered to have a high mortality and survivors suffer from severe mental impairment and fail to thrive. Consequently, surgical procedures are withheld in the early stages of infancy to determine the outcome following the first few months (6).
In Japan, the therapeutic policies for poor long-term life prognosis for trisomy 18 and 13 involve two controversial concepts: i) the provision of thorough affection and care and avoidance of excessive intensive treatment; or ii) the provision of active intensive treatment including resuscitation and surgery according to the clinical conditions of an infant in accordance with the wishes of the affected infant's parents $(14,30)$. However, there was insufficient evidence regarding the improvement of prognosis of trisomy 18 patients treated at the Neonatal Intensive Care Unit (NICU) who underwent surgery. Kosho et al $(14,31)$ studied 24 cases of trisomy 18 treated at the NICU, resulting in improved life prognosis as compared to previously reported data.

After written informed consent was obtained from the family members following genetic counseling, intensive treatment including resuscitation, intra-tracheal intubation, support of artificial ventilation, and surgical procedures was performed for long-term survival of trisomy 18 at the NICU of Dokkyo Medical University School of Medicine. In addition, active support management in the form of home nursing care in cooperation with the family was provided. In this study, in order to certify the clinical details and survival periods of trisomy 18 patients managed at the NICU level, we investigated a retrospective single-center study of 44 patients with trisomy 18 , admitted to the Dokkyo Medical University School of Medicine over a period of $>20$ years.

In addition, prior to performing this study, important factors regarding development of neonatal medicine over a period of $>20$ years was considered. Thus, whether medical progress influenced improvement of the life prognosis of trisomy 18 patients over such a long study period was examined. The patients were divided into two groups and criteria considered included the general condition and life prognosis immediately following the delivery. The results provide useful information concerning genetic counseling for parents/guardians and life prognosis.

\section{Patients and methods}

General. The study comprised 6,183 newborn infants who were admitted to the NICU of Dokkyo Medical University Hospital in Japan, during the period of 1992-2012. The 21-year period was divided into two groups: group A constituted the first 11 years (1992-2002) and group B the second 10 years (2003-2012). Group A and B comprised 2,928 and 3,255 newborn patients, respectively. The newborn infants manifested minor and/or major external malformations or organ malformations that were observed during the clinical examinations by a neonatologist and pediatrician. The infants underwent a congenital chromosomal test and peripheral blood cells obtained were analyzed via the standard method of G-banding karyotype. A breakdown of the patient numerical autosomal trisomies identified 96 patients $(1.55 \%)$, with trisomy $21 ; 44$ patients $(0.71 \%)$ with trisomy 18 including full trisomy, mosaic type and patients with an extra chromosome 18 ; and 17 patients $(0.27 \%)$ with trisomy 13 were admitted to the NICU. Other chromosomal abnormalities exhibited included 2 patients with trisomy 8 mosaicism, 3 patients with 5 p-syndrome and 4 p-syndrome.

In this study, a retrospective single-center study was conducted using NICU medical records from 44 patients 
with trisomy 18 obtained at the Dokkyo Medical University Hospital. Group A comprised 20 patients and group B comprised 22 patients with trisomy 18 . There were no cases of prenatal diagnostic screening for trisomy 18 prior to birth, thus all 44 cases were diagnosed after birth.

Statistical analysis. Statistical analysis was performd to determine any significant differences between groups A and B. The positive effect of the NICU management and treatment was determined when no significant differences were observed for the two groups at delivery but there was a significant difference in the survival prognosis. The following statistical procedure was performed as establishment for it.

Continuous data during pregnancy and delivery were described as mean \pm standard deviation, if normally distributed, or median (interquartile range), if not normally distributed. Comparisons between groups A and B for continuous variables were made using the unpaired t-test, if normally distributed, or Mann-Whitney U test, if not normally distributed. Categorical data were described as number and percentage, and differences were analyzed using Fisher's exact test.

The percentage survival was analyzed using Kaplan-Meier curves after establishing the longest survival time at 1 year. The survival curves were estimated according to the Kaplan-Meier method. The generalized Wilcoxon and log-rank tests were used to determine statistically significant differences for the prognosis of survival time at 180 days, 1 year and the entire investigated period of patients for groups A and B. The time periods were analyzed using SPSS version 22.0 for Windows (IBM Japan, Tokyo, Japan). $\mathrm{P}<0.05$ was considered to indicate a statistically significant difference.

\section{Results}

Clinical details at pregnancy and delivery. The statistical analysis results for groups A and B are shown in Table I. None of the 44 patients with trisomy 18 syndrome had a family history of chromosomal abnormalities. The karyotypes of chromosomal abnormalities associated with chromosome 18 were identified in the 44 patients using a G-banding method. The result of karyotypes included the full type of trisomy 18 in 42 patients (95\%), the mosaic type of trisomy 18 in 1 patient (2\%), and the rare isodicentric chromosome 18 , i.e., 46,XX,idic(18)(p11.31) in 1 patient.

Of the 44 patients, 16 were males and 28 females. None of the patients underwent a prenatal diagnosis using the amniotic fluid marker test for trisomy 18. The term of delivery was 29-42 gestational weeks, with an average of 36.7 gestational weeks. Thirty-six of the patients were born in the Department of Gynecology at the Dokkyo Medical University Hospital and 8 patients were born at other hospital and transferred immediately after birth. Immediately following the delivery, apgar scores of 1 and 5 min were 3 and 6, respectively. The average birth weight was $1585.5 \pm 493.6 \mathrm{~g}$, with a range of 770-2,946 $\mathrm{g}$. The breakdown of birth weight included 4 patients weighing $<1,000 \mathrm{~g}, 17$ patients weighing 1,001-1,500 g, 13 patients weighing 1,501-2,000 g, 9 patients weighing 2,001-2,500 g, and 1 patient weighing $>2,500 \mathrm{~g}$ at delivery. Regarding methods of delivery, 19 patients were delivered via cesarean section and 19 patients via spontaneous delivery.
Three types of statistical analyses were performed for groups A and B. Significant differences were not identified in any of the general conditions examined with the exception of caesarean section which was statistically significant $(\mathrm{P}<0.045)$. Thus, there were no differences between the two groups with regard to the general state of neonate during time of delivery.

Organ malformations, use of mechanical ventilation, and discharge from NICU. Ventilation and surgical treatment as well as discharge from the NICU and prognosis are shown in Tables II and III. Disease manifestations including trisomy 21, 18 and 13, were indicated in the ultrasonography examination during the course of pregnancy, such as intrauterine growth impairment, brain malformation, and congenital heart anomalies. These anomalies were primarily cardiac and brain, and mechanical ventilation as well as surgical procedures were used prior to analysis of outcome and survival (Tables II and III).

As for the congenital heart diseases, 42 of 44 patients (95\%) had some types of cardiac disorder. The breakdown include VSD in 37 patients, PDA in 17 patients, atrial septal defect (ASD) in 14 patients, coarctation of the aorta in 8 patients, double outlet right ventricle in 6 patients, endocardial cushion defect in 3 patients, tricuspid atresia in 2 patients and tetralogy of Fallot (TOF) in 2 patients, mitral valve atresia in 2 patients, transposition of great arteries and hypoplastic left heart syndrome in 1 patient with trisomy 18 . Although 42 cases had a cardiac problem, only one case with TOF underwent surgery following transfer from another hospital. Diuretic medication was prescribed for the management of the cardiac anomalies. Among the major central nervous malformations, 3 patients with trisomy 18 had complicated brain or spinal anomaly. Two patients had spinal meningocele, 1 patient had holoprosencephaly and 1 patient had Dandy-Walker malformation. Sixteen cases of esophageal atresia were also identified, while 4 cases had umbilical hernia. Surgical treatment of gastric fistula was performed in 8 cases of trisomy 18 with complicated severe esophageal atresia with cardiac anomalies.

Mechanical ventilation was performed in 11 cases in 20 samples $(55 \%)$ obtained from group A and 18 cases in 24 samples (75\%) obtained from group B. Thus, treatment using mechanical ventilation showed an increasing trend between group A and B. The primary reason for ventilation therapy was due to respiratory failure with cardiac failure and management of surgery. In-hospital death at NICU occurred in 35 cases, with 4 cases being transferred from another hospital to undergo surgical treatment and 5 cases that were discharged from the NICU were alive. Alive discharge and hospital transfer were increased in group B. The longest survival case was a female patient who survived $>6$ years and 4 months.

Prognosis. Kaplan-Meier survival curves were created (Figs. 1 and 2), based on the data obtained from Table IV. Vertical and horizontal axes of the two figures are the percentage survival and survival days, respectively, setting the longest survival time at 1 year.

Fig. 1 shows the curve for all 44 cases, indicating that one group survived for 4-6 months and the other group survived for a longer period of time.

Fig. 2 is a breakdown of the data shown in Fig. 1, showing the percentage survival curves for groups A and B. The 
Table I. Clinical details at delivery of newborns with trisomy 18 included in this study $(n=44)$.

\begin{tabular}{|c|c|c|c|c|c|c|c|}
\hline Characteristics & No. & $\begin{array}{l}\text { Entire investigation } \\
\text { period (1992-2012) }\end{array}$ & No. & $\begin{array}{c}\text { Group A } \\
(1992-2002)\end{array}$ & No. & $\begin{array}{c}\text { Group B } \\
(2003-2012)\end{array}$ & $\begin{array}{c}\text { P-value } \\
\text { groups } \\
\text { A vs. B }\end{array}$ \\
\hline No. of patients & - & 6,183 & - & 2,928 & - & 3,255 & - \\
\hline Trisomy 18 cases & 44 & 44 & 20 & 20 & 24 & 24 & - \\
\hline Karyotype & 44 & & 20 & & 24 & & $0.493^{\mathrm{a}}$ \\
\hline Full & & 42 & & 20 & & 22 & \\
\hline Others & & 2 & & 0 & & 2 & \\
\hline Gender & 44 & & 20 & & 24 & & $>0.999^{\mathrm{a}}$ \\
\hline Male & & 16 & & 7 & & 9 & \\
\hline Female & & 28 & & 13 & & 15 & \\
\hline Term of delivery (week) & 44 & & 20 & & 24 & & \\
\hline Mean \pm SD & & $36.7 \pm 3.2$ & & $37.3 \pm 3.2$ & & $36.3 \pm 3.2$ & $0.309^{b}$ \\
\hline Median (IQR) & & $37.0(34.0,39.0)$ & & $37.5(35.0,39.8)$ & & $36.5(34.0,39.0)$ & $0.374^{c}$ \\
\hline Delivery place & 44 & & 20 & & 24 & & $0.436^{\mathrm{a}}$ \\
\hline Our hospital & & 36 & & 15 & & 21 & \\
\hline Other hospital & & 8 & & 5 & & 3 & \\
\hline Delivery & 38 & & 15 & & 23 & & $0.045^{\mathrm{a}}$ \\
\hline Cesarean section & & 19 & & 4 & & 15 & \\
\hline Vaginally & & 19 & & 11 & & 8 & \\
\hline \multicolumn{8}{|l|}{ Apgar score (point) } \\
\hline $1 \mathrm{~min}$ & 37 & & 14 & & 23 & & \\
\hline Mean \pm SD & & $3.4 \pm 2.1$ & & $3.2 \pm 2.2$ & & $3.6 \pm 2.1$ & $0.631^{\mathrm{b}}$ \\
\hline Median (IQR) & & $3.0(2.0,5.0)$ & & $2.5(1.8,5.0)$ & & $3.0(2.0,5.0)$ & $0.546^{\mathrm{c}}$ \\
\hline $5 \mathrm{~min}$ & 35 & & 13 & & 22 & & \\
\hline Mean \pm SD & & $6.0 \pm 2.0$ & & $5.7 \pm 2.0$ & & $6.2 \pm 2.0$ & $0.492^{\mathrm{b}}$ \\
\hline Median (IQR) & & $6.0(5.0,7.0)$ & & $5.0(4.0,6.5)$ & & $6.0(5.0,7.0)$ & $0.180^{c}$ \\
\hline Birth weight (g) & 44 & & 20 & & 24 & & \\
\hline Mean \pm SD & & $1585.5 \pm 493.6$ & & $1654.9 \pm 576.8$ & & $1527.8 \pm 415.9$ & $0.402^{\mathrm{b}}$ \\
\hline Median (IQR) & & $1536.0(1186.5,1969.5)$ & & $1552.0(1175.0,2164.0$ & & $1519.0(1186.5,1851.0)$ & $0.525^{\mathrm{c}}$ \\
\hline Categorical data & 44 & & 20 & & 24 & & $0.525^{\mathrm{c}}$ \\
\hline$<1,000$ & & 4 & & 2 & & 2 & \\
\hline $1,000-1,500$ & & 17 & & 7 & & 10 & \\
\hline $1,501-2,000$ & & 13 & & 5 & & 8 & \\
\hline $2,001-2,500$ & & 9 & & 5 & & 4 & \\
\hline$<2.500$ & & 1 & & 1 & & 0 & \\
\hline
\end{tabular}

No., \%; mean \pm standard deviation (SD); median [interquartile range (IQR)]. P-value; ${ }^{\mathrm{a} F i s h e r ' s ~ e x a c t ~ t e s t ; ~}{ }^{\mathrm{b}}$ unpaired t-test; ${ }^{\mathrm{c}} \mathrm{Mann}-\mathrm{Whitney}$ U test.

difference in the curves between groups A and B are evident. The generalized Wilcoxon test was employed to determine the differences between the two curves. The results showed a statistically significant $(<0.05)$ p-value of 0.029 (95\% confidence interval), indicating a better prognosis for group B in the previous 10 years.
Notably, the two curves showed an increasing tendency of percentage survival during the first 1- to 6-month period (Fig. 2). Subsequently, however, the difference in the percentage survival of the two groups indicated a decreasing tendency in the 6-month to 1 year period. We analyzed this tendency using the log-rank test at 180 days and 1 year (Table IV). The 
Table II. Organ malformations, use of mechanical ventilation, surgical treatments and discharge from NICU for patients with trisomy 18 (group A, 1992-2002, n=20).

\begin{tabular}{|c|c|c|c|c|c|}
\hline $\begin{array}{l}\text { (Group A) } \\
\text { Patients }\end{array}$ & $\begin{array}{l}\text { Major organ } \\
\text { malformations }\end{array}$ & $\begin{array}{l}\text { Mechanical } \\
\text { ventilation }\end{array}$ & $\begin{array}{l}\text { Surgical } \\
\text { treatment }\end{array}$ & $\begin{array}{c}\text { Discharge from NICU } \\
\text { (D, dead; } A \text {, alive; } T \text {, transfer) }\end{array}$ & $\begin{array}{l}\text { Survival } \\
\text { (days) }\end{array}$ \\
\hline 1 & TOF PDA EA & - & & $\mathrm{D}$ & 0 \\
\hline 2 & ECD IAA EA & + & & $\mathrm{D}$ & 0 \\
\hline 3 & $\begin{array}{c}\text { TGA ECD } \\
\text { Anal atresia } \\
\text { Defects of both thumb }\end{array}$ & - & & $\mathrm{D}$ & 0 \\
\hline 4 & PDA CoA EA & - & & $\mathrm{D}$ & 2 \\
\hline 5 & $\begin{array}{l}\text { VSD PDA UH } \\
\text { Urachal remnants }\end{array}$ & + & Repair UH & $\mathrm{D}$ & 3 \\
\hline 6 & VSD EA & - & & $\mathrm{D}$ & 3 \\
\hline 7 & EA & + & Gastric fistula & $\mathrm{D}$ & 8 \\
\hline 8 & VSD ASD PDA EA & + & & $\mathrm{D}$ & 17 \\
\hline 9 & VSD EA & - & Gastric fistula & $\mathrm{D}$ & 27 \\
\hline 10 & $\begin{array}{c}\text { VSD CoA } \\
\text { Cleft lip and palate }\end{array}$ & + & $\begin{array}{c}\text { Colostomy } \\
\text { Intestinal segmentectomy }\end{array}$ & $\mathrm{D}$ & 30 \\
\hline 11 & VSD ASD EA & + & & $\mathrm{D}$ & 47 \\
\hline 12 & VSD PDA & + & & $\mathrm{D}$ & 53 \\
\hline 13 & VSD EA & + & Gastric fistula & $\mathrm{D}$ & 56 \\
\hline 14 & ASD PDA CoA UH & + & & $\mathrm{D}$ & 78 \\
\hline 15 & VSD ASD PDA UH & + & & $\mathrm{D}$ & 83 \\
\hline 16 & VSD ASD & - & & A & 102 \\
\hline 17 & EA & - & & $\mathrm{D}$ & 116 \\
\hline 18 & TA & - & & $\mathrm{D}$ & 202 \\
\hline 19 & VSD DWM & + & & $\mathrm{D}$ & 414 \\
\hline 20 & VSD PDA & - & & A & 2311 \\
\hline Total & & $+: 11 /-: 9$ & & D:18/A:2 & \\
\hline
\end{tabular}

VSD, ventriculoseptal defect; ASD, atrial septal defect; PDA, patent ductus arteriosus; CoA, coarctation of the aorta; DORV, double-outlet right ventricle; ECD, endocardial cushion defect; TOF, tetralogy of Fallot; IAA, interruption of aortic arch; TGA, transposition of great arteries; TA, tricuspid atresia; UH, umbilical hernia; EA, esophageal atresia; DWM, Dandy-Walker malformation; NICU, neonatal intensive care unit.

results of the log-rank test indicated a statistically significant $(<0.05)$ p-value of 0.036 at the survival point of 180 days. At the point of 1 year as well as the entire investigated period, the difference was not statistically significant $(<0.05)$ with a p-value of 0.075 and 0.126 .

\section{Discussion}

In this study, we have examined the prognosis of 44 cases of trisomy 18 identified in our NICU over the course of 21 years from 1992 to 2013. Depending on the timing of birth, the subjects with trisomy 18 were divided into two groups, with group A comprising 20 cases, born during the period of 1992-2002, and group B comprising 24 cases, born during the period of 1992-2012. The aim of the present study was to clarify the characteristics and prognosis for each trisomy 18 case, and to compare and consider the life prognosis of the two groups. A comparison of factors such as chromosome type and gender, as well as gestational age as at the time of birth, birth place, vaginal delivery or cesarean section as method of delivery, and Apgar scores based on the 1- and 5-min value, and birth weight was made for groups A and B. Statistical analysis was conducted using three methods to verify the existence of significant differences for groups A and B regarding trisomy 18 for newborns following birth. The results for the A and B trisomy 18 groups showed that, a significant difference was identified only for cesarean section, whereas no significant difference was identified for other factors with regard to the state of the child at birth. Thus, the two groups were considered uniform. A comparison of the two groups using the Kaplan-Meier curve and generalized Wilcoxon test showed an improvement in prognosis in group B. Thus, the progression of medical intervention during the two periods prior to and following the study period is evident due to the life prognosis of patients with trisomy 18 having improved. However, the results of the log-rank test conducted showed that, although a significant difference was observed in the trisomy 18 prognosis at the time of 180 days after birth, at 1 year and the entire survey period after birth, these significant differences could not be confirmed. Thus, additional studies should be performed to confirm the life prognosis and medical intervention of trisomy 18 for neonatal to infantile periods. 
Table III. Organ malformations, use of mechanical ventilation, surgical treatments and discharge from NICU for patients with trisomy 18 (group B, 2003-2012, n=24).

\begin{tabular}{|c|c|c|c|c|c|}
\hline $\begin{array}{l}\text { Group B } \\
\text { Patients }\end{array}$ & $\begin{array}{l}\text { Major organ } \\
\text { malformations }\end{array}$ & $\begin{array}{l}\text { Mechanical } \\
\text { ventilation }\end{array}$ & $\begin{array}{l}\text { Surgical } \\
\text { treatment }\end{array}$ & $\begin{array}{c}\text { Discharge from NICU } \\
\text { (D, dead; A, alive; } T, \text { transfer) }\end{array}$ & $\begin{array}{c}\text { Survival } \\
\text { (days) }\end{array}$ \\
\hline 21 & n.d. & + & & $\mathrm{D}$ & 0 \\
\hline 22 & $\begin{array}{c}\text { VSD ASD PDA IAA EA } \\
\text { Cleft lip and palate } \\
\text { Spurious meningocele }\end{array}$ & + & & $\mathrm{D}$ & 1 \\
\hline 23 & ASD TA & + & & $\mathrm{D}$ & 4 \\
\hline 24 & ECD & + & Gastric fistula & $\mathrm{D}$ & 8 \\
\hline 25 & $\begin{array}{c}\text { VSD PDA } \\
\text { Cleft lip and palate }\end{array}$ & - & & $\mathrm{D}$ & 25 \\
\hline 26 & $\begin{array}{l}\text { VSD ASD DORV UH } \\
\text { Defects of right radius }\end{array}$ & + & & $\mathrm{D}$ & 45 \\
\hline 27 & $\begin{array}{c}\text { VSD CoA } \\
\text { Holoprosencephaly }\end{array}$ & + & & A & 51 \\
\hline 28 & VSD CoA & + & & $\mathrm{D}$ & 60 \\
\hline 29 & VSD ASD PDA EA & + & Gastric fistula & $\mathrm{D}$ & 70 \\
\hline 30 & VSD MS EA & + & Gastric fistula & $\mathrm{T}$ & 92 \\
\hline 31 & VSD ASD PDA & + & & $\mathrm{D}$ & 96 \\
\hline 32 & $\begin{array}{c}\text { VSD PDA CDH } \\
\text { Biliary duct dilatation }\end{array}$ & + & Biliary duct drainage & $\mathrm{D}$ & 108 \\
\hline 33 & VSD ASD EA & + & Gastric fistula & $\mathrm{D}$ & 116 \\
\hline 34 & $\mathrm{TOF}$ & - & Blalock-Taussig operation & $\mathrm{T}$ & 127 \\
\hline 35 & VSD ASD CoA & - & & $\mathrm{D}$ & 132 \\
\hline 36 & $\begin{array}{c}\text { VSD ASD } \\
\text { Laryngeal malacia }\end{array}$ & - & & A & 162 \\
\hline 37 & VSD ASD PDA CoA & + & & $\mathrm{D}$ & 250 \\
\hline 38 & $\begin{array}{c}\text { VSD PDA } \\
\text { Pyloric stenosis }\end{array}$ & - & & $\mathrm{D}$ & 250 \\
\hline 39 & PDA DORV EA & - & & A & 263 \\
\hline 40 & DORV MA HLHS & + & & $\mathrm{T}$ & 263 \\
\hline 41 & $\begin{array}{c}\text { DORV } \\
\text { Spurious meningocele } \\
\text { Defects of radius }\end{array}$ & + & & $\mathrm{D}$ & 309 \\
\hline 42 & VSD PDA & + & & $\mathrm{D}$ & 420 \\
\hline 43 & VSD DORV & + & & $\mathrm{T}$ & 667 \\
\hline 44 & $\begin{array}{l}\text { VSD CoA VORV EA } \\
\text { Imperforate anus }\end{array}$ & + & Gastric fistula & $\mathrm{D}$ & 699 \\
\hline Total & & $+: 18 /-: 6$ & & $\mathrm{D}: 17 / \mathrm{T}: 4 / \mathrm{A}: 3$ & \\
\hline
\end{tabular}

VSD, ventriculoseptal defect; ASD, atrial septal defect; PDA, patent ductus arteriosus; CoA, coarctation of the aorta; DORV, double-outlet right ventricle; ECD, endocardial cushion defect; TOF, tetralogy of Fallot; IAA, interruption of aortic arch; TA, tricuspid atresia; MA, mitral valve atresia; HLHS, hypoplastic left heart syndrome; UH, umbilical hernia; EA, esophageal atresia; CDH, congenital diaphragmatic hernia; NICU, neonatal intensive care unit; n.d, no data.

Previously, despite medical treatment the prognosis for patients with trisomy 18 was lethal reason for chromosomal aberration. Trisomies 21 (Down syndrome), 18 (Edwards syndrome) and 13 (Patau syndrome), as well as other chromosomes are associated with various types of severe anomalies of the mainly brain and viscera, and affected neonate usually do not survive infantile period $(4,5)$. Additionally, complete autosomal trisomies frequently resulted in non-implantation or miscarriage; thus, chromosomal abnormality cases that survive following birth are primarily trisomies 21,18 and 13 (8). Jenderny (32) conducted a study on a German population, and revealed that clinically, the majority of trisomies are unborn due to miscarriage. Pregnancy loss rates ranging from 72 to $87 \%$ for trisomy 18 were demonstrated by Sibiude et al (33) and between 49 and $66 \%$ by Lakovschek et al (34) for trisomy 13 , respectively. It has been previously identified 
Table IV. The analyzed data of the log-rank test at each observation period (group A vs. B).

\begin{tabular}{lccc}
\hline Survival days & Chi-square distribution & df & p-value \\
\hline 180 & 4.381 & 1 & 0.036 \\
365 & 3.173 & 1 & 0.075 \\
Observation end & 2.344 & 1 & 0.126 \\
\hline
\end{tabular}

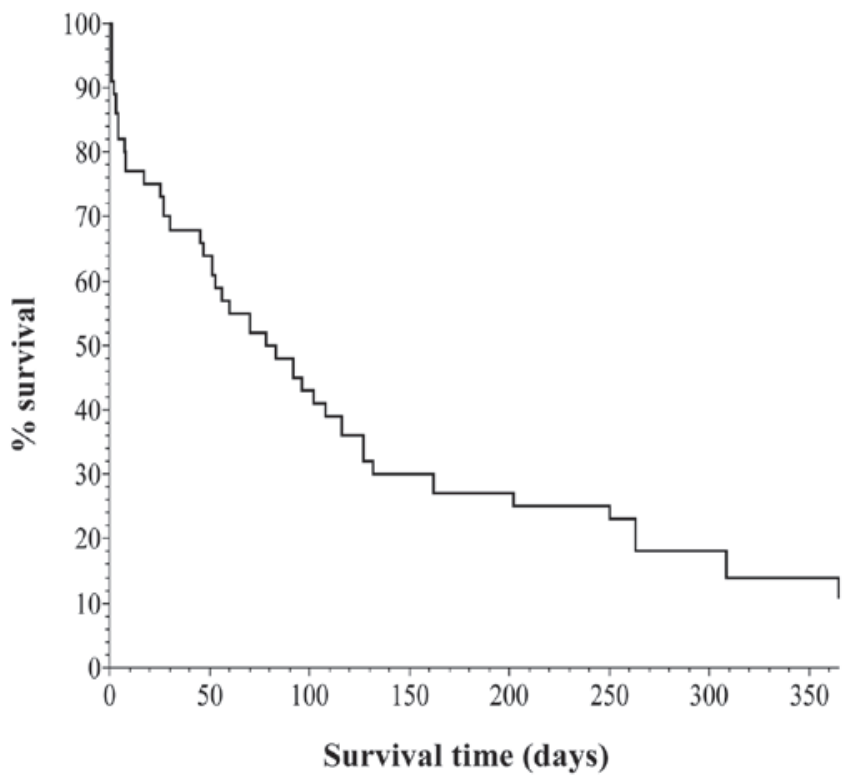

Figure 1. Kaplan-Meier survival curve for patients with trisomy $18(\mathrm{n}=44)$.

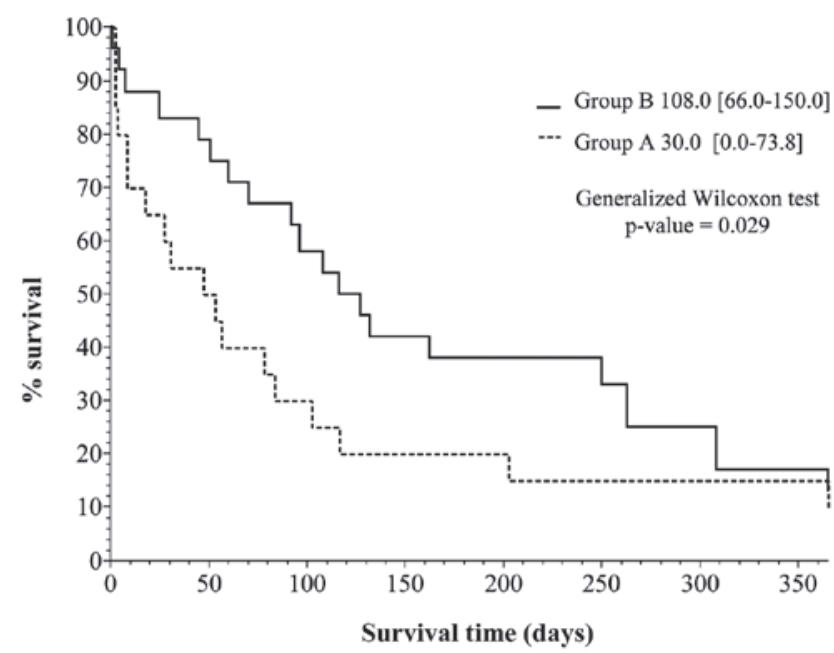

Figure 2. Kaplan-Meier survival curve for patients with trisomy 18 (group A, $\mathrm{n}=20$; group $\mathrm{B}, \mathrm{n}=24$ ).

that trisomy 18 and 13 are the most common trisomies following trisomy 21 (35), with trisomy 18 being the second common trisomy after trisomy 21. Baird and Sadovnick (36) and Noble (37) reported that the average life expectancy of Down syndrome was $>50$ years old due to medical advances in medically advanced countries. However, to the best of our knowledge, the majority of live-born infants with trisomy 18

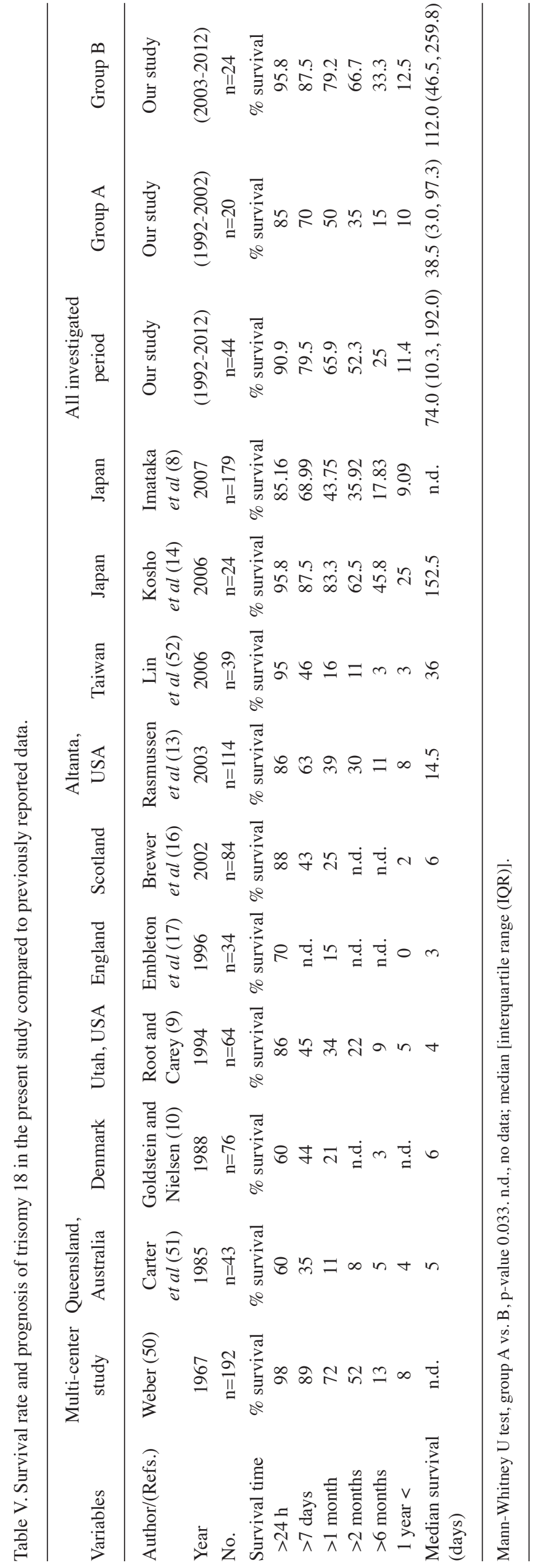


and 13 survive $<1$ year and do not survive to adulthood. In our study, only 5 of the 44 patients survived beyond 1 year of age. Generally, the prognosis of trisomy 18 and 13 are lethal, but long-term survival cases of such trisomies have been sporadically observed. Kelly et al (38) described 20-year-old women and Torres Hinojal et al (39) reported a 14-year-old patient with trisomy 18 . Another case report of long survival of cases of trisomy 18 was conducted by Petek et al (40) who reported on a 19-year-old female and by Smith et al (41) who reported on an 11-year-old female patient and a 21-year-old female patient (42). A search of the literature yielded $\geq 10$ previously reported cases of affected children with trisomy 18 , aged $>10$ years (43-45). In our patient, the oldest individual with trisomy 18 was a 6 -year and 4-month-old female patient with severe intellectual and psychomotor disorder.

Patients with trisomy 18 who show long-term survival present severe psychomotor delay (46). For such cases, aggressive medical treatment in the intensive care unit is controversial as life prognosis is lethal. Only a few studies of patients being managed at NICU have been previously reported. Of these, Kosho et al $(14,31)$ demonstrated that restricted and intensive medical treatments in NICU are valuable in the form of genetic counseling. Since the 1980's, resuscitation and surgical treatments for trisomy 18 have been considered from the standpoints of medical ethics and consideration of quality of life for patients as well as parents and their families, medical economic issues, and medical environment in each countries. In Japan, Nishida and Sakamoto (30) suggested a policy of 'no treatments beyond current treatments' for treatment of newborn infants in 1992. Paris et al (47) also indicated ambiguous ethical issues in the use of life-prolonging interventions for an infant with trisomy 18 in 1992. However, long survival of individuals with chromosomal abnormalities including trisomy 18 and 13, owing to medical progression has since been identified. Notably, treatment policy has also led to gradually changes in medical, sociological, and technical progression. The 4th edition of Smith's textbook in 1988 supports the 'limitation of all medical means for prolongation of life for trisomy 18' (48). However, the 7 th edition of the same textbook in 2013, supports that 'limitation of extraordinary medical means should be seriously considered'. In addition, it advocates that the personal feelings of the parents and the individual circumstances of each infant be taken into consideration (49).

The survival of patients with trisomy 18 and the survival rate from several countries for the period 1967-2010 have been reported in the present study. A long survival period of over 6 months is difficult for patients with trisomy 18, as indicated by Lin et al in 2006 (52) and Weber et al (50) in 1967. On the other hand, the recent findings of Kosho et al (14) and those of our group (8) for populations of Japan, revealed improved life outcome of trisomy 18 . Studies have been recently conducted to investigate treatment procedures and outcome for trisomy 18 (53). Mechanical ventilation treatment was performed in 29 of 44 patients $(65.9 \%)$ by in the present study and the percentage was increased in group B. Paris et al (47) suggested that physicians should be attentive with regard to concentration treatment including ventilation therapy and life-prolonging intervention. Bos et al (29) also report avoidance of emergency surgery in newborns with trisomy 18 . In the present study, patients underwent ventilation therapy owing to respiratory failure and general management. Fenton (54) suggested factors such as quality of life for determining treatment for trisomy 18 . On the other hand, surgical treatment is preferred following informed consent with counseling from the family support meeting (55). Kosho (31) emphasized care of children with trisomy 18 in Japan. Information such as cesarean section (56), general condition (57), health care (58), family (59) and neonatal experience (60) care were important in the treatment of cases with trisomy 18 . However, no clear guideline regarding treatment policy and strategy has been established. In Japan, the surgical treatment of a variety of congenital cardiac diseases (61-65) and esophageal atresia (66) have been performed in patients with trisomy 18 . In addition, treatment for apnea and epilepsy (67-69) were also provided. Graham et al (70) summarized 35 cases of cardiac surgery with trisomy 18 and 13, with increased discharge from the hospital. However, prognosis and quality of life of those patients remain unclear. Janvier et al (71) discussed the issue of ethics regarding an infant-associated VSD. Kaneko et al (62) reported 17 cases of trisomy 18 with cardiac surgery and 14 cases $(82 \%)$ were discharged from NICU leading to a conclusion that it was effective in decreasing mortality in NICU due to cardiac failure. NICU management with ventilation and surgical procedures has potential to improve the short-term outcome of $<1$ year in trisomy 18. In the present study, an improvement in the outcome of 6 months from delivery by various treatments including mechanical ventilation and surgical procedure was observed. However, additional studies on a larger number of cases should be performed concerning treatment strategy and genetic counseling to the family with a newborn with trisomy 18.

Although the present study had a small sample size, our data provide one of the larger single-center studies currently available. The results of the present study provide information concerning genetic counseling for parents and their families and life prognosis, prior to applying intensive management to newborns with trisomy 18

\section{Acknowledgements}

We would like to express our gratitude and appreciation to all the NICU medical staff, Dokkyo Medical University Hospital, Tochigi, Japan.

\section{References}

1. Edwards JH, Harnden DG, Cameron AH, Crosse VM and Wolff OH: A new trisomic syndrome. Lancet 1: 787-790, 1960.

2. Smith DW, Patau K, Therman E and Inhorn SL: A new autosomal trisomy syndrome: multiple congenital anomalies caused by an extra chromosome. J Pediatr 57: 338-345, 1960.

3. Cereda A and Carey JC: The trisomy 18 syndrome. Orphanet J Rare Dis 7: 81, 2012.

4. Carey JC: Trisomy 18 and trisomy 13 syndrome. In: Management of genetic syndromes. Allanson J and Cassidy S (eds). 2nd edition. Wiley, Hoboken, NJ, pp555-568, 2005.

5. Menkes JH and Falk RE: Chapter 3 Chromosomal anomalies and contiguous gene syndrome. In: Child Neurology. Menkes $\mathrm{JH}$ and Sarnat HB (eds). 6th edition. Lippincott Williams and Wilkins, Philaderphia, PA, pp241-275, 2000.

6. Jones KL (ed): Tirsomy 18 syndrome. In: Smith's recognized patterns of human malformation. 6th edition. Elsevier Saunders, Philaderphia, PA, pp18-21, 2006. 
7. Imataka G, Yamanouchi $\mathrm{H}$ and Arisaka O: Dandy-Walker syndrome and chromosomal abnormalities. Congenit Anom (Kyoto) 47: 113-118, 2007.

8. Imataka G, Nitta A, Suzumura H, Watanabe H, Yamanouchi H and Arisaka O: Survival of trisomy 18 cases in Japan. Genet Couns 18: 303-308, 2007.

9. Root S and Carey JC: Survival in trisomy 18. Am J Med Genet 49: $170-174,1994$

10. Goldstein H and Nielsen KG: Rates and survival of individuals with trisomy 13 and 18. Data from a 10-year period in Denmark. Clin Genet 34: 366-372, 1988.

11. Forrester MB and Merz RD: Trisomies 13 and 18: prenatal diagnosis and epidemiologic studies in Hawaii, 1986-1997. Genet Test 3: 335-340, 1999.

12. Bergin A, McManus SP, Clarke TA and Moloney M: Trisomy 18: a nine year review. Ir J Med Sci 157: 5-7, 1988.

13. Rasmussen SAA, Wong LYC, Yang Q, May KM and Friedman JM: Population-based analyses of mortality in trisomy 13 and trisomy 18. Pediatrics 111: 777-784, 2003.

14. Kosho T, Nakamura T, Kawame H, Baba A, Tamura M and Fukushima Y: Neonatal management of trisomy 18: clinical details of 24 patients receiving intensive treatment. Am J Med Genet A 140: 937-944, 2006.

15. Baty BJ, Blackburn BL and Carey JC: Natural history of trisomy 18 and trisomy 13: I. Growth, physical assessment, medical histories, survival, and recurrence risk. Am J Med Genet 49: 175-188, 1994.

16. Brewer CM, Holloway SH, Stone DH, Carothers AD and FitzPatrick DR: Survival in trisomy 13 and trisomy 18 cases ascertained from population based registers. J Med Genet 39: e54, 2002.

17. Embleton ND, Wyllie JP, Wright MJ, Burn J and Hunter S: Natural history of trisomy 18. Arch Dis Child Fetal Neonatal Ed 75: F38-F41, 1996

18. Crider KS, Olney RS and Cragan JD: Trisomies 13 and 18 Population prevalences, characteristics, and prenatal diagnosis, metropolitan Atlanta, 1994-2003. Am J Med Genet A 146A: 820-826, 2008

19. Irving $C$, Richmond $S$, Wren $C$, Longster $C$ and Embleton ND: Changes in fetal prevalence and outcome for trisomies 13 and 18 a population-based study over 23 years. J Matern Fetal Neonatal Med 24: 137-141, 2011.

20. Van Dyke DC and Allen M: Clinical management considerations in long-term survivors with trisomy 18 . Pediatrics 85: 753-759, 1990.

21. Niedrist D, Riegel M, Achermann J and Schinzel A: Survival with trisomy 18 - data from Switzerland. Am J Med Genet A 140 952-959, 2006

22. Vendola C, Canfield M, Daiger SP, Gambello M, Hashmi SS, King T, Noblin SJ, Waller DK and Hecht JT: Survival of Texas infants born with trisomies 21, 18, and 13. Am J Med Genet A 152A: 360-366, 2010

23. Naguib KK, Al-Awadi SA, Moussa MAA, Bastaki L, Gouda S, Redha MA, Mustafa F, Tayel SM, Abulhassan SA and Murthy DSK: Trisomy 18 in Kuwait. Int J Epidemiol 28: 711-716, 1999.

24. Kuroki Y and Kurosawa K: No sex differences in 18 trisomy births in the Kanagawa Birth Defects Monitoring Program. Congenit Anom (Kyoto) 44: 97-98, 2004.

25. Jones KL (ed): Tirsomy 18 syndrome. In: Smith's recognized patterns of human malformation. 5th edition. Elsevier Saunders, Philaderphia, PA, pp14-15, 1997.

26. De Souza E, Halliday J, Chan A, Bower C and Morris JK: Recurrence risks for trisomies 13, 18, and 21. Am J Med Genet A 149A: 2716-2722, 2009.

27. Fisher JM, Harvey JF, Lindenbaum RH, Boyd PA and Jacobs PA Molecular studies of trisomy 18. Am J Hum Genet 52: 1139-1144 1993.

28. Norup M: Attitudes towards abortion among physicians working at obstetrical and paediatric departments in Denmark. Prenat Diagn 18: 273-280, 1998

29. Bos AP, Broers CJ, Hazebroek FW, van Hemel JO, Tibboel D, Wesby-van Swaay E and Molenaar JC: Avoidance of emergency surgery in newborn infants with trisomy 18. Lancet 339: 913-915, 1992.

30. Nishida $\mathrm{H}$ and Sakamoto S: Ethical problems in neonatal intensive care unit - medical decision making on the neonate with poor prognosis. Early Hum Dev 29: 403-406, 1992.

31. Kosho T: Care of children with trisomy 18 in Japan. Am J Med Genet A 146A: 1369-1371, 2008
32. Jenderny J: Chromosome aberrations in a large series of spontaneous miscarriages in the German population and review of the literature. Mol Cytogenet 7: 38, 2014.

33. Sibiude J, Gavard L, Floch-Tudal C and Mandelbrot L: Perinatal care and outcome of fetuses with trisomies 13 and 18 following a parental decision not to terminate the pregnancy. Fetal Diagn Ther 29: 233-237, 2011.

34. Lakovschek IC, Streubel B and Ulm B: Natural outcome of trisomy 13 , trisomy 18 , and triploidy after prenatal diagnosis. Am J Med Genet A 155A: 2626-2633, 2011.

35. Imataka G, Suzumura H and Arisaka O: Diagnosis of sex chromosomal abnormalities in neonatal intensive care units. Genet Couns 24: 399-403, 2013

36. Baird PA and Sadovnick AD: Life expectancy in Down syndrome adults. Lancet 2: 1354-1356, 1988.

37. Noble J: Natural history of Down's syndrome: a brief review for those involved in antenatal screening. J Med Screen 5: 172-177, 1998.

38. Kelly M, Robinson BW and Moore JW: Trisomy 18 in a 20-year-old woman. Am J Med Genet 112: 397-399, 2002

39. Torres Hinojal MC, Marugán de Miguelsanz JM and Rodríguez Fernández LM: Fourteen-year survival in a patient with Edwards syndrome. An Pediatr (Barc) 63: 458-459, 2005 (In Spanish).

40. Petek E, Pertl B, Tschernigg M, Bauer M, Mayr J, Wagner K and Kroisel PM: Characterisation of a 19-year-old 'long-term survivor' with Edwards syndrome. Genet Couns 14: 239-244, 2003.

41. Smith A, Silink M and Ruxton T: Trisomy 18 in an 11 year old girl. J Ment Defic Res 22: 277-286, 1978.

42. Smith A, Field B and Learoyd BM: Trisomy 18 at age 21 years. Am J Med Genet 34: 338-339, 1989.

43. Hook EB, Lehrke R, Roesner A and Yunis JJ: Trisomy-18 in a 15-year-old female. Lancet 2: 910-911, 1965.

44. Surana RB, Bain HW and Conen PE: 18-Trisomy in a 15-year-old girl. Am J Dis Child 123: 75-77, 1972.

45. Houlihan OA and O'Donoghue K: The natural history of pregnancies with a diagnosis of trisomy 18 or trisomy 13; a retrospective case series. BMC Pregnancy Childbirth 13: 209, 2013.

46. Baty BJ, Jorde LB, Blackburn BL and Carey JC: Natural history of trisomy 18 and trisomy 13: II. Psychomotor development. Am J Med Genet 49: 189-194, 1994.

47. Paris JJ, Weiss AH and Soifer S: Ethical issues in the use of life-prolonging interventions for an infant with trisomy 18 J Perinatol 12: 366-368, 1992

48. Jones KL (ed): Tirsomy 18 syndrome. In: Smith‘s recognized patterns of human malformation. 4th edition. Elsevier Saunders, Philaderphia, PA, pp16-17, 1988.

49. Jones KL (ed): Tirsomy 18 syndrome. In: Smith's recognized patterns of human malformation. 7th edition. Elsevier Saunders, Philaderphia, PA, pp14-17, 2013.

50. Weber WW: Survival and the sex ratio in trisomy 17-18. Am J Hum Genet 19: 369-377, 1967.

51. Carter PE, Pearn JH, Bell J, Martin N and Anderson NG: Survival in trisomy 18. Life tables for use in genetic counselling and clinical paediatrics. Clin Genet 27: 59-61, 1985.

52. Lin HY, Lin SP, Chen YJ, Hung HY, Kao HA, Hsu CH, Chen MR, Chang JH, Ho CS, Huang FY, et al: Clinical characteristics and survival of trisomy 18 in a medical center in Taipei, 1988-2004. Am J Med Genet A 140: 945-951, 2006.

53. Ishitsuka K, Matsui H, Michihata N, Fushimi K, Nakamura T and Yasunaga $\mathrm{H}$ : Medical procedures and outcomes of Japanese patients with trisomy 18 or trisomy 13: Analysis of a nationwide administrative database of hospitalized patients. Am J Med Genet A 167A: 1816-1821, 2015.

54. Fenton LJ: Trisomy 13 and 18 and quality of life: Treading 'softly'. Am J Med Genet A 155A: 1527-1528, 2011.

55. Kosho T, Kuniba H, Tanikawa Y, Hashimoto Y and Sakurai H: Natural history and parental experience of children with trisomy 18 based on a questionnaire given to a Japanese trisomy 18 parental support group. Am J Med Genet A 161A: 1531-1542, 2013.

56. Schneider AS, Mennuti MT and Zackai EH: High cesarean section rate in trisomy 18 births: a potential indication for late prenatal diagnosis. Am J Obstet Gynecol 140: 367-370, 1981.

57. Imai K, Uchiyama A, Okamura T, Ago M, Suenaga H, Sugita E, Ono H, Shuri K, Masumoto K, Totsu S, et al: Differences in mortality and morbidity according to gestational ages and birth weights in infants with trisomy 18. Am J Med Genet A 167: 2610-2617, 2015

58. Walker LV, Miller VJ and Dalton VK: The health-care experiences of families given the prenatal diagnosis of trisomy 18 . J Perinatol 28: 12-19, 2008 
59. Janvier A, Farlow B and Wilfond BS: The experience of families with children with trisomy 13 and 18 in social networks. Pediatrics 130: 293-298, 2012

60. Bruns DA: Neonatal experiences of newborns with full trisomy 18. Adv Neonatal Care 10: 25-31, 2010.

61. Kaneko Y, Kobayashi J, Yamamoto Y, Yoda H, Kanetaka Y, Nakajima Y, Endo D, Tsuchiya K, Sato H and Kawakami T: Intensive cardiac management in patients with trisomy 13 or trisomy 18. Am J Med Genet A 146A: 1372-1380, 2008

62. Kaneko Y, Kobayashi J, Achiwa I, Yoda H, Tsuchiya K, Nakajima Y, Endo D, Sato H and Kawakami T: Cardiac surgery in patients with trisomy 18. Pediatr Cardiol 30: 729-734, 2009.

63. Kobayashi J, Kaneko Y, Yamamoto Y, Yoda H and Tsuchiya K: Radical surgery for a ventricular septal defect associated with trisomy 18. Gen Thorac Cardiovasc Surg 58: 223-227, 2010.

64. Maeda J, Yamagishi H, Furutani Y, Kamisago M, Waragai T, Oana S, Kajino H, Matsuura H, Mori K, Matsuoka R, et al: The impact of cardiac surgery in patients with trisomy 18 and trisomy 13 in Japan. Am J Med Genet A 155A: 2641-2646, 2011.

65. Muneuchi J, Yamamoto J, Takahashi Y, Watanabe M, Yuge T, Ohno T, Imoto Y, Sese A and Joo K: Outcomes of cardiac surgery in trisomy 18 patients. Cardiol Young 21: 209-215, 2011.
66. Nishi E, Takamizawa S, Iio K, Yamada Y, Yoshizawa K, Hatata T, Hiroma T, Mizuno S, Kawame H, Fukushima Y, et al: Surgical intervention for esophageal atresia in patients with trisomy 18 . Am J Med Genet A 164A: 324-330, 2014.

67. Kumada T, Nishii R, Higashi T, Oda N and Fujii T: Epileptic apnea in a trisomy 18 infant. Pediatr Neurol 42: 61-64, 2010.

68. Kumada T, Maihara T, Higuchi Y, Nishida Y, Taniguchi Y and Fujii T: Epilepsy in children with trisomy 18. Am J Med Genet A 161A: 696-701, 2013.

69. Fukasawa T, Kubota T, Tanaka M, Asada H, Matsusawa K, Hattori T, Kato Y and Negoro T: Apneas observed in trisomy 18 neonates should be differentiated from epileptic apneas. Am J Med Genet A 167A: 602-606, 2015.

70. Graham EM, Bradley SM, Shirali GS, Hills CB and Atz AM; Pediatric Cardiac Care Consortium: Effectiveness of cardiac surgery in trisomies 13 and 18 (from the Pediatric Cardiac Care Consortium). Am J Cardiol 93: 801-803, 2004.

71. Janvier A, Okah F, Farlow B and Lantos JD: An infant with trisomy 18 and a ventricular septal defect. Pediatrics 127: 754-759, 2011. 